\title{
Small molecule conversion of toxic oligomers to non-toxic $\beta$-sheet-rich amyloid fibrils
}

Nat. Chem. Biol. 2011 Nov 20. doi: 10.1038/nchembio.719.

Jan Bieschke ${ }^{1 \#}$, Martin Herbst ${ }^{1,2 \#}$, Thomas Wiglenda ${ }^{1}$, Ralf P. Friedrich ${ }^{1}$, Annett Boeddrich ${ }^{1}$, Franziska Schiele ${ }^{1}$, Daniela Kleckers ${ }^{1}$, Juan Miguel Lopez del Amo ${ }^{9}$, Björn Grüning ${ }^{7}$, Qinwen Wang ${ }^{4 *}$, Michael R. Schmidt ${ }^{1}$, Rudi Lurz ${ }^{3}$, Roger Anwyl ${ }^{4}$, Sigrid Schnoegl ${ }^{1}$, Marcus Fändrich ${ }^{5}$, Ronald F. Frank ${ }^{8}$, Bernd Reif ${ }^{9,10}$, Stefan Günther ${ }^{7}$, Dominic M. Walsh ${ }^{6}$, Erich E. Wanker ${ }^{1 \ddagger}$

$1 \quad$ Neuroproteomics, Max Delbrueck Center for Molecular Medicine, Berlin, Germany

2 Department of Neurology, Charité-Universitätsmedizin Berlin, Germany

3 Max Planck Institute for Molecular Genetics, Berlin, Germany

$4 \quad$ Department of Physiology, Trinity College, Dublin, Republic of Ireland

$5 \quad$ Max Planck Research Unit for Enzymology of Protein Folding, Halle (Saale), Germany

6 Laboratory for Neurodegenerative Research, The Conway Institute for Biomolecular and Biomedical Research, University College Dublin, Republic of Ireland

7 Institute for Pharmaceutical Sciences, University of Freiburg, Germany

8 Department of Chemistry, Helmholtz Center for Infection Research, Braunschweig, Germany

$9 \quad$ Leibniz Institute for Molecular Pharmacology, Berlin, Germany

10 Technical University Munich, Germany

\# Both authors contributed equally

present address: Department of Physiology and Pharmacology, Medical School, Ningbo University, Ningbo, China

‡ To whom correspondence should be addressed: ewanker@mdc-berlin.de

\begin{abstract}
Several lines of evidence indicate that pre-fibrillar assemblies of amyloid- $\beta(A \beta)$ polypeptides such as soluble oligomers or protofibrils rather than mature, end-stage amyloid fibrils cause neuronal dysfunction and memory impairment in Alzheimer's disease (AD). This suggests that reducing the prevalence of transient intermediates by small molecule mediated stimulation of amyloid polymerization might decrease toxicity. Here, we demonstrate the acceleration of $A \beta$ fibrillogenesis through the action of the orcein-related small molecule O4, which directly binds to hydrophobic amino acid residues in A $\beta$ peptides and stabilizes the self-assembly of seeding-competent, $\beta$-sheet-rich protofibrils and fibrils. Strikingly, O4-mediated acceleration of amyloid fibril formation efficiently decreased the concentration of small, toxic $A \beta$ oligomers in complex, heterogeneous aggregation reactions. In addition, $\mathrm{O} 4$ treatment suppressed inhibition of long-term potentiation by $A \beta$ oligomers in hippocampal brain slices. These results support the hypothesis that small, diffusible pre-fibrillar amyloid species rather than mature fibrillar aggregates are toxic for mammalian cells.
\end{abstract}




\section{Introduction}

Accumulation of extracellular amyloid plaques is a key feature of Alzheimer's disease (AD) pathogenesis ${ }^{1}$. Amyloid plaques are mainly formed of amyloid- $\beta(A \beta)$ polypeptides of 39-42 amino acids, which are produced by proteolytic cleavage of the amyloid- $\beta$ precursor protein (APP), a membrane protein of largely unknown cellular function ${ }^{2}$.

$A \beta$ monomers self-assemble into amyloid fibrils by nucleation-dependent polymerization, a process that is accelerated by the addition of preformed amyloid fibrils ${ }^{3}$. The formation of $\beta$-sheet-rich amyloid fibrils is a complex multistep process associated with cellular toxicity ${ }^{4}$. It involves the assembly of various transient and intransient, on- and off-pathway aggregate species, whose structures, sizes and biological activities are not well defined. In vitro studies have demonstrated that $A \beta$ monomers can convert into small, $\beta$-sheet-rich oligomers and protofibrils that are on-pathway to the assembly of ordered amyloid fibrils ${ }^{5,6}$. In addition, evidence was presented that $A \beta$ monomers at low temperatures can assemble into spherical, non- $\beta$-sheet oligomers, suggesting that they are off-pathway aggregation products ${ }^{7}$. At higher temperatures however, these structures, transform readily into larger $\beta$-sheet-rich aggregates ${ }^{7}$, indicating that structural conversion of non- $\beta$-sheet $A \beta$ oligomers into $\beta$-sheet-rich amyloid fibrils is possible. Small soluble, pre-fibrillar amyloid assemblies such as $A \beta$ oligomers cause memory impairment and are likely to be more toxic than large, end-stage, amyloid fibrils ${ }^{2,8}$. Discriminating among different types of $A \beta$ aggregate species is therefore an important challenge to clarify the role of transient oligomers and protofibrils in amyloid pathogenesis ${ }^{4}$.

Biochemical and cell biological studies indicate that amyloid formation pathways can be manipulated with small molecules 9 Osmolytes such as trimethylamine $\mathrm{N}$-oxide or glycerol as well as short peptides were shown to accelerate $A \beta$ fibrillogenesis 10,11 , while small molecules such as scyllo-inositol stabilize the formation of oligomers and protofibrils 12. In contrast, compounds such as dopamine or calmidazolium chloride were found to block amyloid fibrillogenesis ${ }^{13-15}$. Substances selectively inhibiting $A \beta$ oligomerization ${ }^{16}$, redirecting amyloid formation pathways 17,18 or remodeling preformed amyloid structures 19 were also reported. Thus, small molecules can be powerful tools for the modulation of amyloid formation cascades, stabilizing aggregate species or influencing structural changes in aggregate pathways ${ }^{20}$.

If small, diffusible aggregation products are indeed the toxic species in $A D^{2}$, accelerating nucleation and fibril assembly with small molecules should reduce their toxicity. To test this hypothesis, we have searched for compounds that promote $A \beta$ polymerization using a membrane filter assay. Here, we show that the natural compound mixture orcein and the related substance $\mathrm{O} 4$ are potent stimulators of $A \beta$ fibrillogenesis. Strikingly, compound-mediated amyloid polymerization was accompanied by a dramatic reduction of toxic on-pathway aggregation intermediates. Detailed biochemical and biophysical studies revealed that $\mathrm{O} 4$ directly binds to hydrophobic regions in the amyloid- $\beta$ 1-42 $\left(A \beta_{42}\right)$ peptide which are critical for efficient amyloid polymerization ${ }^{21}$. Our data indicate that $\mathrm{O} 4$ binding to $A \beta_{42}$ peptides stabilizes the assembly of $\beta$-sheetrich protofilaments that efficiently nucleate the formation of amyloid fibrils ${ }^{3}$. The potential implications of these results for the treatment of $A D$ and other amyloid diseases are discussed.

\section{Results}

\section{Identification of $\boldsymbol{A} \beta$ aggregation stimulators.}

In order to find chemical compounds that promote $A \beta_{42}$ amyloidogenesis, a membrane filter retardation assay (FRA) was established that allows the quantification of large, SDS-stable protein aggregates. It is illustrated in the Supplementary Results (Supplementary Fig. 1a). Using this method, we screened a focused library of $\sim 300$ chemical compounds that were previously identified as modulators of polyglutamine-mediated huntingtin exon 1 aggregation ${ }^{22}$. We detected $6 \quad A \beta_{42}$ aggregation-promoting compounds, three of which shared a phenoxazine structure. The natural dye orcein, which most effectively accelerated spontaneous $A \beta_{42}$ aggregation in vitro, was studied further (Fig. 1a and b, Supplementary Fig. 1b).

Orcein is a mixture of closely related substances such as the $\alpha-, \beta-$ and $\gamma$-amino-orceins and orceimines $\left(\mathbf{1}-\mathbf{6}\right.$, Supplementary Fig. 1b) ${ }^{23}$. In order to identify a pure compound that stimulates $A \beta_{42}$ aggregation, we searched for orcein-related small molecules in compound libraries and databases. 18 chemical compounds were finally selected and tested (Supplementary Table 1), and the substance 2,8-bis-(2,4-dihydroxy-phenyl)-7hydroxy-phenoxazin-3-one, termed O4 (7), was identified as a potent $A \beta_{42}$ aggregation accelerator (Fig. 1a and b). Quantitative analysis of timeresolved aggregation data revealed that $\mathrm{O} 4$ reduces the lag phase of $A \beta_{42}$ polymerization (Sup Supplementary Fig. 2a), suggesting that it targets early aggregate species in the amyloid formation cascade ${ }^{3}$. No stimulation of aggregation was observed by FRA when the control proteins APP, Hsp70 and Hsp90 were incubated for $4 \mathrm{~d}$ at $37^{\circ} \mathrm{C}$ with $\mathrm{O} 4$ (Supplementary Fig. $2 \mathrm{~b}$ ), indicating that the effect on $A \beta_{42}$ peptides is specific and $\mathrm{O} 4$ does not promote the aggregation of unrelated human proteins. Finally, the aggregation-promoting effect of O4 was confirmed with more physiological $A \beta_{42}$ concentrations (100 nM, Supplementary Fig. 2c and d). 


\section{O4 promotes assembly of $\beta$-sheet-rich amyloid fibrils.}

As FRAs do not discriminate between fibrillar and non-fibrillar aggregates, we next examined the morphology of O4-generated protein assemblies by transmission electron microscopy (TEM). After an incubation period of $4 \mathrm{~d}$, worm-like $A \beta_{42}$ protofibrils ${ }^{24}$ with a length of $\sim 30-150 \mathrm{~nm}$ and a diameter of $\sim 5$ $\mathrm{nm}$ were predominantly detected in untreated aggregation reactions (Fig. 1c). In contrast, mostly longer amyloid fibrils (>500 nm) were observed in O4-treated samples, indicating accelerated amyloid formation. A similar result was obtained after an incubation period of $7 \mathrm{~d}$ (Fig. 1c). Quantification of fibrils, protofibrils and oligomers after $48 \mathrm{~h}$ confirmed these results (Fig. 1d). The amount of long amyloid fibrils $(27 \%)$ was significantly larger $(p$ $<1^{*} 10^{-5}$ ) in 04 treated samples than in untreated control samples (1.3\%). At the same time, the fraction of oligomeric structures was reduced in $04-$ treated aggregation reactions $\left(p<1^{*} 10^{-4}\right)$.

Previous studies have demonstrated that insoluble $A \beta_{42}$ fibrils have a characteristic cross- $\beta$-sheet conformation ${ }^{25}$. Therefore, we investigated whether O4 treatment influences the structure of $A \beta_{42}$ amyloid fibrils using circular dichroism (CD) spectroscopy ${ }^{18}$. We found that both 04 -treated and untreated $A \beta_{42}$ fibrils have CD spectra characteristic of $\beta$-sheet-rich structures (Fig. 1e), indicating that compoundmediated acceleration of $A \beta_{42}$ aggregation does not substantially alter fibril conformation. Next, the conversion of unstructured $A \beta_{42}$ monomers into $\beta$ sheet-rich aggregates was investigated. The change in CD signal at $218 \mathrm{~nm}$ over the course of $3,000 \mathrm{~s}$ was monitored for O4-treated and untreated $A \beta_{42}$ peptides. A monoexponential data fit yielded a time constant of $\tau=150 \pm 40 \mathrm{~s}$ for O4-treated samples, while a time constant of $\tau=350 \pm 30$ s was obtained for untreated samples, indicating that $\mathrm{O} 4$ accelerates the transition of unstructured $A \beta_{42}$ molecules into larger $\beta$-sheet-rich aggregates (Fig. 1f).

We also investigated whether O4-generated $A \beta_{42}$ fibrils are seeding-competent structures. Amyloid fibrils were produced in vitro in the presence and absence of $\mathrm{O} 4$ and added as seeds to an excess of unpolymerized $A \beta_{42}$ monomers. The formation of $\beta$ sheet-rich amyloid fibrils was monitored over time using a Thioflavin $\mathrm{T}$ (ThT) dye binding assay ${ }^{26}$. We found that both 04 -generated $A \beta_{42}$ seeds and untreated seeds accelerate amyloid polymerization (Fig. 1g), indicating that $\mathrm{O} 4$ treatment results in the formation of seeding-competent $A \beta_{42}$ structures.

Finally, the effect of $\mathrm{O} 4$ on template-mediated $A \beta_{42}$ aggregation was confirmed using a cell-based assay. $\mathrm{CHO}$ cells overexpressing mutant human APP protein ${ }^{15}$ were treated with preformed $A \beta_{42}$ fibrils ${ }^{19,27}$, and subsequently incubated for $48 \mathrm{~h}$ with $5 \mu \mathrm{M}$ 04. Formation of SDS-stable, insoluble $A \beta$ aggregates was monitored by FRA. The amount of insoluble $A \beta$ aggregates in $O 4$ treated cells was 4-fold higher than in untreated ones (Fig. $1 \mathrm{~h}$ and Supplementary Fig. 2e), indicating that the compound stimulates $A \beta$ polymerization in cell-free and cell-based assays.

\section{O4 promotes formation of stable amyloid aggregates.}

The stability of amyloid structures in compoundtreated $A \beta_{42}$ aggregation reactions was analyzed by SDS-PAGE and silver staining (Fig. 2a). In the absence of $\mathrm{O} 4$, aggregation products resolved to monomers ( $\sim \mathrm{kDa})$, small oligomers ( 10-12 and 14-16 kDa), medium-size oligomers ( 100-150 kDa) and large aggregates $(>250 \mathrm{kDa})$ in SDS gels. However, in the presence of the compound the relative amount of medium-size, SDS-stable oligomers and large aggregates was increased, while the amounts of monomers and small oligomers were decreased (Fig. 2a). This supports the view that $\mathrm{O} 4$ treatment promotes the formation of large SDS-stable fibrillar structures (Fig. 1c and d) that do not efficiently disassemble under denaturing conditions.

We then investigated whether $\mathrm{O} 4$ treatment influences the protease resistance of $A \beta_{42}$ fibrils. Aggregates generated in the presence or absence of $\mathrm{O} 4\left(4-21 \mathrm{~d}\right.$ at $\left.37^{\circ} \mathrm{C}\right)$ were treated with different concentrations of proteinase $\mathrm{K}\left(30 \mathrm{~min}\right.$ at $\left.37^{\circ} \mathrm{C}\right)$ and subsequently analyzed by FRA. We found that SDS and proteinase $K$ resistant $A \beta_{42}$ aggregates appear much faster in the presence of $\mathrm{O} 4$ than in its absence (Fig. 2b), supporting the results with denaturing SDS-gels (Fig. 2a).

\section{O4 converts $A \beta_{42}$ oligomers into SDS-stable aggregates.}

To examine whether $\mathrm{O} 4$ converts $A \beta_{42}$ oligomers into fibrils, we first tested whether it binds to different types of aggregate species. Peptide preparations highly enriched in unstructured $A \beta_{42}$ monomers ${ }^{18}$, spherical, $\beta$-sheet-rich oligomers ${ }^{28}$ or large $\beta$-sheetrich amyloid fibrils ${ }^{18}$ were produced and characterized by ThT fluorescence (Supplementary Fig. 3a), atomic force microscopy (Supplementary Fig. 3b) and CD spectroscopy (Supplementary Fig. 3c). Then, these samples were incubated with $\mathrm{O} 4$ and spotted onto a nitrocellulose membrane. After washing with buffer $\mathrm{O} 4$ binding was examined. As $\mathrm{O} 4$ is a blue dye, its binding to amyloid aggregates can be detected colorimetrically (Fig. 2c). We found that $\mathrm{O} 4$ readily stains $\beta$-sheet-rich oligomeric and fibrillar $A \beta_{42}$ aggregates, while monomers were hardly colored, indicating that the compound preferentially associates with $\beta$-sheet-rich amyloid assemblies. Membranes were finally analyzed using the anti-A $\beta$ antibody 6E10 (Supplementary Fig. 3d and $e)$, demonstrating that comparable amounts of $A \beta_{42}$ preparations were spotted.

We next investigated whether $\mathrm{O} 4$ is covalently cross-linked to $\beta$-sheet-rich $A \beta_{42}$ assemblies, using a 
nitro-tretrazolium blue (NBT) staining assay ${ }^{29}$. This method was shown recently to allow the detection of $A \beta_{42}$-bound EGCG molecules ${ }^{18}$. We found that EGCG but not $\mathrm{O} 4$ treated aggregates are stained with NBT (Supplementary Fig. 3f), indicating that $\mathrm{O} 4$ does not promote the cross-linking of $A \beta_{42}$ peptides. This result was also confirmed by incubation of $A \beta_{42}$ assemblies with trifluor acetic acid (TFA), indicating that both $\mathrm{O} 4$ treated and untreated $A \beta_{42}$ aggregates are dissolved equally well by the solvent (Supplementary Fig. 3g).

To assess the affinity of $\mathrm{O} 4$ to $\beta$-sheet rich $A \beta_{42}$ oligomers, compound $(0.4-200 \mu \mathrm{M})$ treated aggregate species (equivalent to monomer concentrations of 3,6 and $12 \mu \mathrm{M}$ ) were spotted onto nitrocellulose membranes. Binding of 04 to $A \beta_{42}$ oligomers was quantified colorimetrically (Supplementary Fig. 4a). Quantitative analysis of data revealed half-maximal binding $\left(E_{50}\right)$ constants of $50 \pm 2 \mu \mathrm{M}, 25 \pm 1 \mu \mathrm{M}$, and $3.5 \pm 0.1$, respectively (Fig. 2d), which indicates that a single site binding model is not sufficient to explain compound binding. A cooperative binding model with a Hill coefficient of $\mathrm{n}=4$, however, allowed a reasonable representation of data, suggesting that $\mathrm{O} 4$ binding to oligomers requires $4 \quad A \beta_{42}$ molecules. No or very weak $\mathrm{O} 4$ binding was observed for control proteins such as APP, Hsp70 and Hsp90 (Supplementary Fig. 4b), indicating that the compound preferentially associates with $A \beta_{42}$ oligomers.

We then investigated whether $\mathrm{O} 4$ treatment influences the assembly of small $A \beta_{42}$ oligomers ${ }^{30}$. $A \beta_{42}$ monomers were incubated for $24 \mathrm{~h}$ at $6-8^{\circ} \mathrm{C}$ in the presence and absence of 04 ; formation of oligomers was subsequently analyzed by TEM. In soluble fractions of untreated aggregation reactions large numbers of predominantly spherical $A \beta_{42}$ oligomers with a diameter of 5-15 $\mathrm{nm}$ were observed (Fig. 2e), while such structures were rarely detected in $\mathrm{O} 4$ treated samples. Compound treated samples, however, contained multiple protofibrillar structures and amorphous $A \beta_{42}$ aggregates, suggesting that $O 4$ binding converts oligomers into larger aggregates. This result was confirmed when pellet fractions were analyzed by TEM (Fig. 2e). O4 treated fractions contained long amyloid fibrils. Such structures were undetectable in untreated fractions, which rather contained smaller protofibrillar aggregates (Fig. 2e).

The effect of $\mathrm{O} 4$ on early $\beta$-sheet-rich aggregate species was also visible by SDS-PAGE and immunoblotting. Compound treatment in a concentration-dependent manner stimulated the conversion of small $A \beta_{42}$ oligomers and protofibrils into larger SDS-stable amyloid aggregates (Fig. 2f), supporting the results observed by TEM (Fig. 2e).

Finally, we examined the effect of $\mathrm{O} 4$ on oligomers that are recognized by the conformation-specific A11 antibody ${ }^{31}$. Soluble $A \beta_{42}$ peptides were incubated in the presence and absence of $\mathrm{O} 4$ for $48 \mathrm{~h}$ at $37^{\circ} \mathrm{C}$; the resulting aggregate species were analyzed by dot blotting. A11-reactive oligomers were detected in the absence but not in the presence of the chemical compound (Fig. 2g), suggesting that $\mathrm{O} 4$ either masks the epitope for antibody binding or coverts A11-reactive oligomers into larger structures which cannot be detected with this antibody ${ }^{31}$.

\section{O4 binds to hydrophobic regions in $A \beta_{42}$ peptides.}

To define potential $O 4$ binding regions in $A \beta_{42}$, peptide arrays ${ }^{32}$ were produced and probed with the chemical compound (Supplementary Fig. 5a, Fig. 3a). We found that $\mathrm{O} 4$ most strongly interacts with short $A \beta_{42}$ peptides that contain non-polar, hydrophobic amino acids (e.g., peptide 12: VHHQKLVFFA, aa 12-21 or peptide 24: VGSNKGAIIG, aa 24-33), while peptides with polar amino acids (e.g., peptide 1: DAEFRHDSGY, aa 110) were recognized very weakly or not at all (Fig. $3 a)$. This suggests that hydrophobic regions in $A \beta_{42}$ peptides are preferentially targeted by the chemical compound.

We next investigated whether the position of hydrophobic amino acids in peptides influences $\mathrm{O} 4$ binding. Two short peptides were synthesized (A: KLVFFAE, aa $16-22$ of $A \beta_{42}$ and $B$ : EFAVFLK, a scrambled version of $\mathrm{A}$ ) and $\mathrm{O} 4$ binding was quantified colorimetrically. We observed that $\mathrm{O} 4$ readily interacts with peptide $A$ but not with the control peptide B (Supplementary Fig. $5 b$ and $c$ ), indicating that the compound interaction requires a certain order of hydrophobic amino acids. In comparison, the unspecific dye amido black detects both peptides equally well on filter membranes.

Finally, we investigated the interaction between $\mathrm{O} 4$ and $A \beta_{40}$ peptides by NMR spectroscopy. We employed $A \beta_{40}$ in these experiments as its aggregation propensity is considerably reduced in comparison to $A \beta_{42}$, making it more amenable to solution state NMR studies ${ }^{3}$. ${ }^{15} \mathrm{~N}$-labeled $A \beta_{40}$ was titrated with $\mathrm{O} 4$, and ${ }^{1} \mathrm{H}-{ }^{15} \mathrm{~N}$ HSQC spectra were recorded. Fig. $3 \mathrm{~b}$ shows the spectrum obtained using a 4-fold molar excess of 04 . Resonances involving residues $17-20$ and $31-37$ exhibited pronounced shifts when compared to resonances obtained in the absence of $\mathrm{O} 4$ (Fig. 3c), confirming the results with peptide arrays (Fig. 3a). Thus, our studies demonstrate that $\mathrm{O} 4$ specifically targets hydrophobic regions critical for efficient amyloid polymerization ${ }^{33}$ in $A \beta_{40}$ and $A \beta_{42}$ peptides.

Previous studies indicate that effects of small molecules on amyloidogenesis might be caused by compound aggregates ${ }^{34}$. We therefore investigated whether $\mathrm{O} 4$ forms aggregates in aqueous solution. Analytical ultracentrifugation revealed that $\sim 30 \%$ of O4 molecules in solution are aggregated and have an apparent mass of 10-20 kDa (Supplementary Fig. $6 a)$, suggesting that larger $\mathrm{O} 4$ aggregates rather than monomers might promote $A \beta_{42}$ polymerization. To test this hypothesis, we removed the large 04 aggregates from aqueous solutions by filtration using a $3 \mathrm{kDa}$ cut-off membrane (Supplementary 
Fig. 6a) and subsequently analyzed the resulting $\mathrm{O} 4$ solutions in established $A \beta_{42}$ aggregation assays. We found that both filtered and unfiltered $\mathrm{O} 4$ solutions readily promote spontaneous amyloid polymerization in cell-free assays (Supplementary Fig. 6b and c), suggesting that high molecular weight $\mathrm{O} 4$ aggregates are not a prerequisite for the compound effects on $A \beta_{42}$ aggregation.

Finally, we applied NMR to investigate the potential structures of $\mathrm{O} 4$ molecules in aqueous solutions. We observed that the ${ }^{1} \mathrm{H}$-NMR spectra of $\mathrm{O} 4$ molecules in filtered and unfiltered solutions are almost identical (Supplementary Fig. 6d). Moreover, an equilibrium between an $\mathrm{O} 4: \mathrm{A} \beta$ complex and soluble $\mathrm{O} 4$ and $\mathrm{A} \beta$ molecules was observed by NMR in titration experiments, arguing against a strong contribution of aggregated 04 molecules to $A \beta$ binding.

\section{O4 changes the affinity of antibodies for $A \beta_{42}$ fibrils.}

To examine whether $\mathrm{O} 4$ influences the morphology of $A \beta_{42}$ fibrils, compound-generated structures (incubation for $5 \mathrm{~d}$ at $37^{\circ} \mathrm{C}$ ) were analyzed with dot blot assays using the monoclonal anti- $A \beta$ antibodies $6 \mathrm{E} 10$ and $4 \mathrm{G} 8{ }^{35}$. We observed that $4 \mathrm{G} 8$ binding to O4-generated $A \beta_{42}$ aggregates was reduced compared to untreated aggregates (Fig. 4a and b), suggesting that the compound alters the antibody binding to amino acids $18-22$ in $A \beta_{42}$ peptides. In contrast, no such effect was observed with the antibody $6 \mathrm{E} 10$ that specifically recognizes the $\mathrm{N}$ terminal amino acids 4-9 in $A \beta_{42}$ peptides.

We also examined whether O4-generated $A \beta_{42}$ aggregates can be detected with the conformation specific antibody B10 that preferentially recognizes amyloid fibrils but does not bind to monomers or small oligomers ${ }^{36}$. As shown in Fig. $4 \mathrm{c}$ and $\mathrm{d}, \mathrm{O} 4$ treatment results in $A \beta_{42}$ aggregate species with reduced $B 10$ immunoreactivity, suggesting that the antibody epitope on the surface of $A \beta_{42}$ aggregates is altered upon compound binding.

\section{Predicting the binding regions of 04 on $A \beta_{42}$ fibrils.}

Using a computational docking approach, we assessed how $\mathrm{O} 4$ might interact with a 3D structural model of $A \beta_{42}$ fibrils ${ }^{25,7}$. To introduce some flexibility for the ligand the docking method Glide was applied ${ }^{37}$. Remarkably, in all adequate docking solutions the compound $\mathrm{O} 4$ was placed parallel to the long axis of amyloid fibrils, connecting 4-5 $\beta$-sheet units (Fig. $5 a)$. This suggests that $\mathrm{O} 4$ promotes amyloidogenesis because it stabilizes the intermolecular interactions of multiple $A \beta_{42}$ molecules.

Our docking studies predicted that $\mathrm{O} 4$ preferentially targets three hydrophobic binding grooves (aa 20$21,33-35$ and $35-37$ ) on the surface of $A \beta_{42}$ fibrils (Supplementary Table 2), suggesting that the compound has more than one favourable docking site on amyloid fibrils (Fig. 5a and b). A detailed analysis revealed that the conjugated $\pi$-electron system of the planar oxazine ring in $\mathrm{O} 4$ most likely is critical for its association with hydrophobic grooves on the surface of $A \beta_{42}$ fibrils. In case of the $A \beta_{42}$ binding site at aa 20-21 the oxazine ring of $\mathrm{O} 4$ might directly interact with the aromatic rings of phenylalanine 20 (F20, Fig. 5c), while at binding sites aa 33-35 and 35-37 an interaction between the oxazine ring and the glycines 33 and 37 is most likely. However, at all three favourable docking sites hydrogen bonds between hydroxyl groups in $\mathrm{O} 4$ and peptide carbonyl groups may also contribute to the compound interaction.

Finally, we also modeled docking of the $\mathrm{O} 4$ related compounds 5-methlybenzene-1,3-diol (O5), phenoxazine (06) and 7-hydroxy-phenoxazin-3-one (O8) that do not promote spontaneous $A \beta_{42}$ aggregation (Supplementary Tables 1 and 2). Modelling predicted that the compounds $\mathrm{O} 5$ and $\mathrm{O} 8$, similar to $\mathrm{O} 4$, bind to the hydrophobic regions in $A \beta_{42}$ fibrils (aa 20-21, 33-35 and 35-37), while the compound 06 most likely does not associate (Supplementary Table 2). This suggests that the dihydroxy-phenyl groups in 04, which are linked to the phenoxazinone unit and are absent from 08 , might be critical for its aggregation promoting effect on $\mathrm{A} \beta_{42}$ molecules.

\section{Acceleration of fibril formation reduces $A \beta_{42}$ toxicity.}

To study whether O4-mediated conversion of aggregation intermediates into stable amyloid fibrils influences $A \beta_{42}$ toxicity, SH-SY5Y neuroblastoma cells were incubated for $48 \mathrm{~h}$ with soluble $A \beta_{42}$ peptides and different concentrations of $\mathrm{O} 4$. Viability of cells was examined using a 3-(4,5dimethylthiazol-2yl)-2,5-diphenyltetrazolium bromide (MTT) assay ${ }^{38}$. We found that incubation of cells with $A \beta_{42}$ peptides caused a pronounced inhibition of MTT reduction ( $50 \%)$, indicative of impaired cellular metabolic activity. This effect, however, was suppressed when $\mathrm{O} 4$ was added to the culture medium (Fig. 6a). In contrast, the compound O8, which does not promote amyloid fibrillogenesis in cell-free assays (Supplementary Table 2), did not rescue $A \beta_{42}$ toxicity (Supplementary Fig. 7a).

To investigate whether $\mathrm{O} 4$ treatment influences cellassociated $A \beta_{42}$ aggregation, cell culture media were analyzed by SDS-PAGE and silver staining (Fig. 6b). In untreated samples, relatively large amounts of small $A \beta_{42}$ monomers and oligomers $(\sim 12 \mathrm{kDa})$ were detected. The abundance of these structures, however, diminished in $\mathrm{O} 4$ treated samples. At the same time, $\mathrm{O} 4$ addition increased the abundance of larger aggregate structures, suggesting that the compound promotes amyloidogenesis. A reduction of toxicity was also observed when $A \beta_{42}$ treated primary cortical neurons were incubated with $\mathrm{O} 4$, confirming the results with the SH-SY5Y 
neuroblastoma cells (Suppl. Supplementary Fig. 7b and $\mathrm{c}$ ).

Next, we examined whether O4-mediated stimulation of extracellular amyloidogenesis influences intracellular aggregation of $A \beta_{42}$ peptides, which are readily taken up by mammalian cells. $A \beta_{42}$ peptides labeled with the fluorescent dye Alexa 633 were added to human neuroblastoma SH-EP cells in the presence and absence of $\mathrm{O} 4$ and formation of intracellular aggregates was quantified by immunofluorescence microscopy (Supplementary Fig. 7d). 04 treatment caused a $\sim 3$-fold reduction of intracellular $A \beta_{42}$ aggregates compared to untreated controls (Supplementary Fig. 7e), indicating that compound-mediated stimulation of extracellular amyloid polymerization alters the uptake and intracellular formation of $A \beta_{42}$ aggregates.

Finally, we investigated whether $\mathrm{O} 4$ treatment influences $A \beta_{42}$-mediated impairment of hippocampal long-term potentiation (LTP) in rat brain slices ${ }^{15,39}$. A preparation of $A \beta_{42}$ peptides containing monomers and small oligomers was added to hippocampal brain slices and LTP was measured in the CA1 area. In agreement with previous studies ${ }^{39}$, we found that small $A \beta_{42}$ oligomers block LTP in brain slices (Fig. $6 c$ ). This effect, however, was suppressed when $\mathrm{O} 4$ was added to samples, suggesting that compoundmediated acceleration of aggregation rescues the $A \beta_{42}$-induced dysfunction of synaptic plasticity.

\section{Discussion}

Previous investigations have demonstrated that chemical agents can be used to perturb amyloid formation pathways ${ }^{22}$. Most of these studies focused on small molecules or $\beta$-sheet breaker peptides that inhibit or slow down spontaneous amyloid polymerization ${ }^{1,40}$. In a few studies compounds or small peptides that promote amyloid fibrillogenesis have been found ${ }^{11,41,42}$. However, it mostly remains unclear whether monomers, oligomers or protofibrillar structures are specifically targeted by modulators of amyloid aggregation ${ }^{43,44}$ and whether compound effects on certain aggregate species (e.g. protofibrils) are toxic or beneficial for mammalian cells ${ }^{13}$.

In this study, we have searched for small molecules that promote spontaneous $A \beta_{42}$ assembly. This undertaking was motivated by recent observations that small, diffusible aggregate species (oligomers and/or protofibrils) are more toxic for neuronal cells than mature fibrils or end-stage amyloid plaques ${ }^{45}$. Accordingly, compounds that target small, onpathway aggregate species and promote their conversion into larger fibrils might reduce neurotoxicity. Utilizing a FRA ${ }^{45}$, we discovered und that the natural dye orcein efficiently promotes $A \beta_{42}$ polymerization (Fig. 1b). Orcein is a compound mixture consisting of $\sim 14$ related small molecules ${ }^{23}$ that has been used as a food coloring since the Middle Ages. As the orcein components might have different biological activities, we searched for pure chemicals with similar properties, which lead to the identification of the small molecule O4 (2,8-bis-(2,4dihydroxy-phenyl)-7-hydroxy-phenoxazin-3-one) that very efficiently stimulated $A \beta_{42}$ polymerization.

Previous studies have demonstrated that $A \beta_{42}$ amyloidogenesis is a highly complex, multistep process, which involves the sequential formation of different types of amyloid species such as oligomers, protofibrils and mature fibrils ${ }^{45} . A \beta_{42}$ monomers first assemble into oligomers, which over time convert into protofibrils and long amyloid fibrils with a typical $\beta$-sheet structure. It is currently believed that small $\beta$-sheet-rich spherical oligomers are on-pathway precursors of protofibrils and fibrils ${ }^{5}$, while unstructured (non- $\beta$-sheet-rich) $A \beta_{42}$ oligomers 7 are most likely off-pathway aggregation products. However, recent investigations showed that non- $\beta$ sheet $A \beta_{42}$ oligomers produced at low temperatures can convert into ordered $\beta$-sheet-rich amyloid fibrils at higher temperatures ${ }^{7}$. Thus, it seems plausible that spherical $A \beta_{42}$ oligomers with different morphologies and structures can transform into larger $\beta$-sheet-rich amyloid aggregates.

Our data indicate that $\mathrm{O} 4$ binds to spherical, onpathway $\beta$-sheet-rich $A \beta_{42}$ oligomers and promotes their conversion into larger amyloid fibrils (Fig. 2c-e and Supplementary Fig. 3a-e). This effect is most probably caused by an interaction of the compound with hydrophobic residues in the central region of $A \beta_{42}$ peptides. We suggest that $\mathrm{O} 4$ stimulates the conversion of oligomers into amyloid fibrils because it increases the hydrophobicity on the surface of amyloid oligomers, leading to more efficient intermolecular interactions and aggregation. $\mathrm{O} 4$ is an aromatic compound that potentially can form $\pi$-stacking interactions with the hydrophobic phenylalanine residues $F 19$ and $F 20$ in $A \beta_{42}$ peptides (Fig. 3a and $\mathrm{C}$ ). These amino acids were previously shown to be critical for efficient amyloid polymerization in vitro ${ }^{21}$. However, our data do not exclude the possibility that other hydrophobic amino acids in the $A \beta_{42}$ peptide such as the glycines G33 and G37 are also important for the conversion of small oligomers into protofibrils and fibrils (Fig. 3a and c). The exchange of glycines with other amino acids has previously been shown to influence the rate of spontaneous amyloid polymerization ${ }^{46}$.

Our data also suggest that $\mathrm{O} 4$ directly binds to hydrophobic regions in protofibrils and mature amyloid fibrils (Fig. 3). This is supported by computational docking studies, predicting that the compound associates with hydrophobic grooves on the surface of amyloid structures (aa 20-21, 33-35, 35-37) that run parallel to the long fibril axis (Fig. 5). Strikingly, our docking studies also predict that $\mathrm{O} 4$ requires 4-5 $A \beta_{42}$ molecules for its association with amyloid fibrils (Fig. 5), suggesting that the compound promotes fibrillogenesis by stabilizing small $\beta$-sheet-rich protofibrillar structures that lie directly en route to fibril formation. Compound 
binding to protofibrils and fibrils could alter the equilibrium between monomers, oligomers, protofibrils and mature fibrils in dynamic aggregation reactions, leading to the accumulation of larger amounts of end-stage amyloid structures. Our findings that O4-treated amyloid fibrils are more stable than untreated fibrils support this hypothesis (Fig. 2a and b). A model depicting the binding of $\mathrm{O} 4$ to small $\beta$-sheet-rich structures and its potential effects on amyloid polymerization is proposed in Fig. 7.

A comparison of our results with previous investigations on aggregation modulators indicate that the mechanism of action of $\mathrm{O} 4$ is similar to that of methylene blue, which also promotes $A \beta_{42}$ fibrillogenesis in cell-free assays ${ }^{16}$. Interestingly, the authors of that study propose that methylene blue influences $A \beta_{42}$ oligomerization and fibrillogenesis independently and suggest that these two processes are not directly linked. We do not come to such a conclusion. Rather, our data indicate that $A \beta_{42}$ oligomerization and fibrillogenesis are linked and that O4-mediated stimulation of aggregation is responsible for the reduction of toxic, on-pathway amyloid oligomers. However, more detailed timeresolved studies with well-defined $A \beta_{42}$ aggregate species are necessary to compare the results obtained with $\mathrm{O} 4$ and methylene blue.

While $\mathrm{O} 4$ promotes the formation of long amyloid fibrils the compound calmidazolium chloride (CLC) was shown to stabilize protofibrillar structures ${ }^{13}$. A stabilization of $\beta$-sheet-rich, nontoxic, spherical $A \beta$ conformations was observed with the compound scyllo-inositol ${ }^{47}$, while the polyphenol EGCG was shown to convert $A \beta_{42}$ peptides into non-toxic, unstructured oligomers ${ }^{18}$. A similar result was obtained more recently with the compound resveratrol that selectively remodels soluble oligomers and fibrils of $A \beta_{42}$ peptides into offpathway conformers ${ }^{48}$. Thus, small molecules can have different effects on $A \beta_{42}$ polymerization, leading to the stabilization of aggregate species with very distinct conformations, morphologies and biological properties.

Our studies indicate that the compound $\mathrm{O} 4$ accelerates $A \beta_{42}$ fibril formation and thereby decreases the concentration of transient, soluble $A \beta_{42}$ oligomers that are toxic for mammalian cells. Our biochemical and cell-biological investigations therefore support the oligomer toxicity hypothesis, as they suggest that small aggregates appearing early in the amyloid formation cascade rather than large fibrils are the main toxic species in protein misfolding diseases ${ }^{15}$. However, it currently remains unclear whether compound-mediated stimulation of amyloid fibrillogenesis in vivo may be a useful therapeutic strategy with beneficial effects on neuronal dysfunction. For instance, it needs to be investigated whether the chemical compound can influence the aggregation of low nanomolar concentrations of $A \beta$ peptides in vivo. Moreover, it needs to be seen whether compound-induced accelerated deposition of $A \beta_{42}$ aggregates has beneficial effects on disease pathogenesis in $A D$ models. Experimental evidence supporting such a view has been presented previously, indicating that accelerated $A \beta$ fibrillization reduces oligomer levels and functional deficits in $A D$ mouse models ${ }^{49}$. We suggest that compounds like 04 , which bind to $\beta$ sheet-rich amyloid structures might reduce their toxicity by preventing the abnormal interactions of small aggregate species with cellular proteins. Moreover, it seems possible that compounds that are bound to aggregates promote their degradation. Further in vivo studies with $A D$ transgenic fly and mouse models will be necessary to address the question of whether compounds that promote fibrillogenesis in vitro such as $\mathrm{O} 4$ may be useful for therapy development.

\section{Materials and Methods}

Materials, toxicity assays and additional procedures are described in the Supplementary Methods.

\section{Protein aggregation.}

For aggregation reactions, an $A \beta_{42}$ stock solution (1 $\mathrm{mM}$ in DMSO) was diluted in phosphate buffer (100 $\mathrm{mM}$ sodium phosphate, $10 \mathrm{mM} \mathrm{NaCl}, \mathrm{pH} 7.4$ ) to 15 $\mu \mathrm{M}$ and incubated in $1.5 \mathrm{ml}$ Eppendorf tubes (Eppendorf, Germany) at $37^{\circ} \mathrm{C}$. Generation of soluble $A \beta_{42}$ oligomers was performed as described 30. A $\beta_{42}$ DMSO stock solutions were diluted in Ham's F12 medium without phenol red at a final peptide concentration of $100 \mu \mathrm{M}$; after brief vortexing samples were incubated at $4-6^{\circ} \mathrm{C}$ for $24 \mathrm{~h}$. Alternatively, $A \beta_{42}$ oligomers were prepared as described in ${ }^{28}$ by diluting DMSO stock solution to a final $A \beta_{42}$ concentration of $110 \mu \mathrm{M}$ in $10 \mathrm{mM}$ HEPES buffer $\mathrm{pH}$ 7.4. Samples were incubated in a glass vial with a micro stir bar at $37^{\circ} \mathrm{C}$ for $24 \mathrm{~h}$ and subsequently centrifuged (Beckman Coulter Microfuge $\mathrm{R}$, rotor $\mathrm{F} 241.5 \mathrm{P}$ ) at $13,000 \mathrm{rpm}$. All concentrations of oligomeric or fibrillar $A \beta$ species refer to the equivalent concentration of $A \beta$ monomers.

\section{Quantification of insoluble amyloid aggregates.}

In filter retardation assays (FRAs) $60 \mu \mathrm{l}$ of $A \beta_{42}$ aggregation reactions were added to an equal volume of $4 \%$ sodium dodecyl sulfate (SDS) and $100 \mathrm{mM}$ dithiothreitol (DTT) and samples were boiled at $98^{\circ} \mathrm{C}$ for $5 \mathrm{~min} .85 \mu \mathrm{l}$ of the heat denatured samples were filtered through a cellulose acetate membrane with $0.2 \mu \mathrm{m}$ pores (OE66, Schleicher and Schuell, Germany). Membranes were blocked in Tris-buffered saline containing $3 \%$ skim milk. Aggregates retained on the filter membrane were detected using the 6E10 antibody (1:5,000; Sigma, Deisenhofen, Germany) and secondary antibodies conjugated to either horseradish peroxidase or 
alkaline phosphatase (Promega, Germany). Proteinase K (final concentration of $10-200 \mu \mathrm{g} / \mathrm{ml}$ ) was added to $A \beta_{42}$ aggregation reactions after 4 or 7 $\mathrm{d}$ of incubation at $37^{\circ} \mathrm{C}$. After incubation for $30 \mathrm{~min}$ at $37^{\circ} \mathrm{C}$ with proteinase $\mathrm{K}$ samples were denatured and analyzed by FRA.

\section{Acknowledgements}

We thank S. Kostka, G. Grelle, and S. Rautenberg for technical assistance; A. Otto for analysis of compound mixtures by mass spectrometry and $M$. Peters for expert discussions. This work was supported by grants from DFG (BI 1409/2-1) to J.B., BMBF (NGFN-Plus 01GS08132) to J.B. and E.E.W.; DFG (WA1151/5-1), BMBF (NGFN1/2, BioFuture, GO-Bio), EU (APOPIS, EUROSCA, EuroSpin and SynSys) and the Helmholtz Association (MSBN, HeIMA) to E.E.W.

\section{Author contributions}

M.H., J.B., R.P.F., A.B., F.S., D.K., M.R.S. performed aggregation experiments; T.W., provided chemistry expertise; J.M.L. and B.R. performed NMR experiments; B.G. and S.G. performed computational docking studies; Q.W., R.A., and D.M.W. contributed LTP experiments; R.L. helped with EM; M.F contributed a conformation-specific antibody; R.F.F. produced peptide arrays; S.S., J.B. and E.E.W edited the manuscript; E.E.W designed the study and wrote the manuscript.

\section{Conflict of interest}

The authors declare no financial conflict of interest. 


\section{Figures}

a
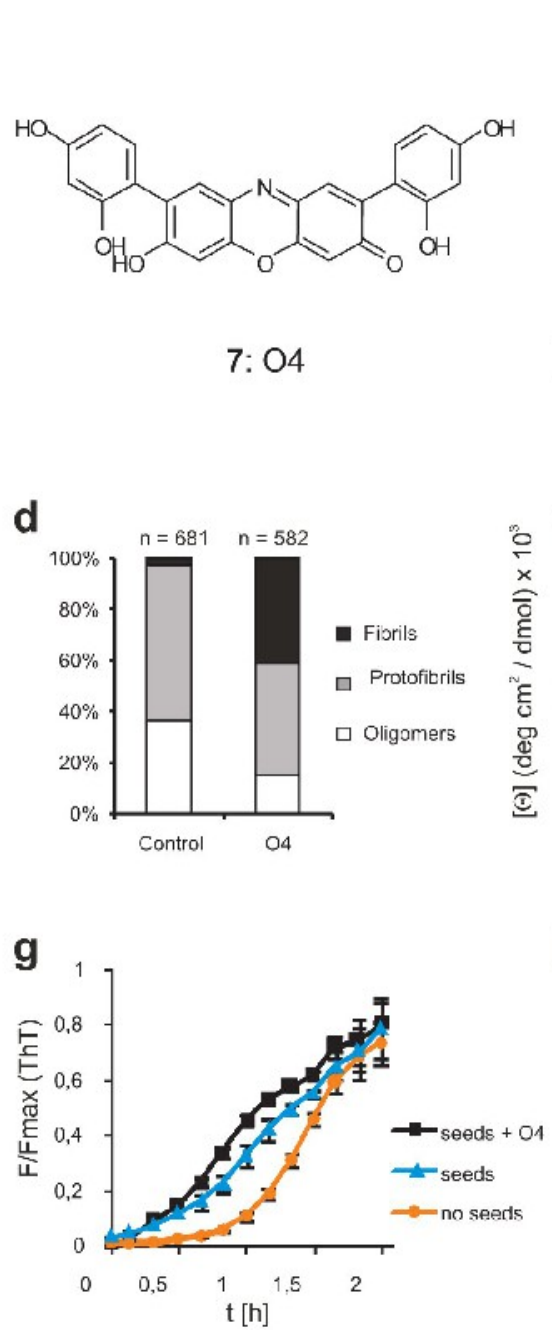

b

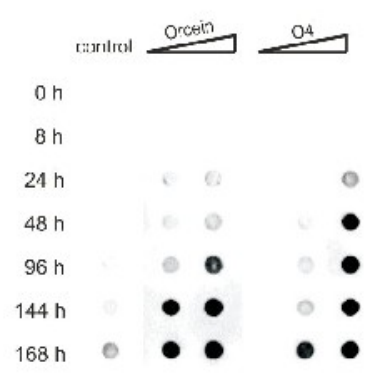

C

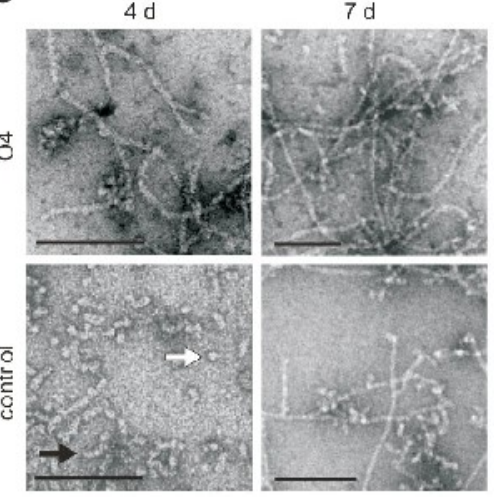

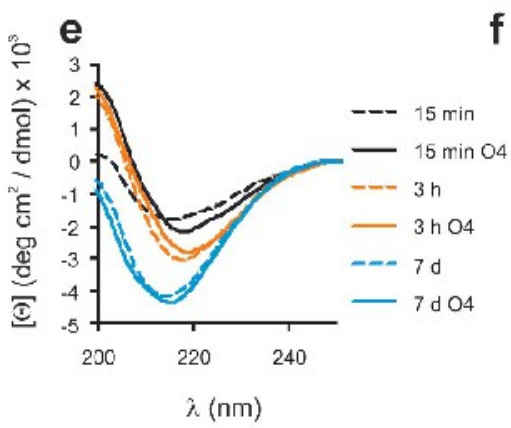

h
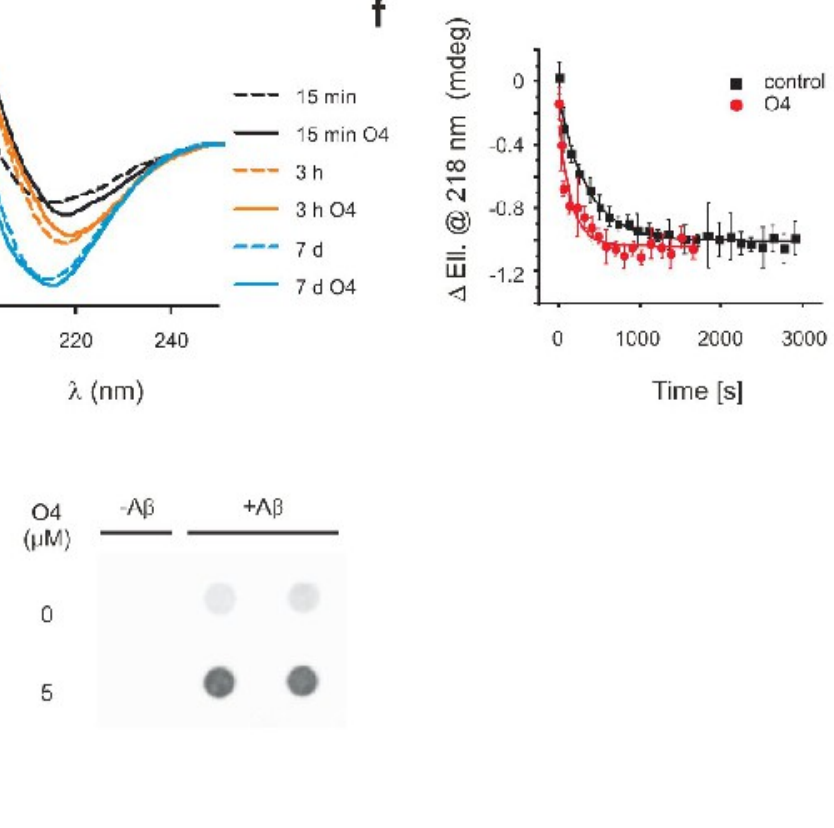

Fig. 1. Identification and characterization of compounds that accelerate $A \beta_{42}$ aggregation. a, Structural formula of 04 . b. Effects of orcein or $\mathrm{O} 4$ on $A \beta_{42}$ aggregate formation monitored by FRA. $A \beta_{42}(15 \mu M)$ was incubated with orcein or $\mathrm{O} 4$ at equimolar concentrations or 5-fold molar excess; SDS-stable aggregates were detected using the antibody $6 \mathrm{E} 10$. c. Analysis of $\mathrm{O} 4(150 \mu \mathrm{M})$ treated $\mathrm{A} \beta_{42}(15 \mu \mathrm{M})$ aggregation reactions by TEM. Bars indicate $100 \mathrm{~nm}$. Arrows indicate oligomers (white) or protofibrils (black). d, Quantification of $A \beta_{42}$ aggregate species observed after $48 \mathrm{~h}$ by TEM. e. Analysis of $A \beta_{42}$ aggregates by $C D$ spectroscopy. $A \beta_{42}(15 \mu \mathrm{M})$ aggregates were produced with an equimolar concentration of $\mathrm{O} 4$ at $37^{\circ} \mathrm{C}$. $\mathbf{f}$, Change in ellipticity at $218 \mathrm{~nm}$ during incubation of monomeric $A \beta_{42}(15 \mu \mathrm{M})$ with $\mathrm{O} 4(75 \mu \mathrm{M})$. CD data were fitted by monoexponential decay functions with time constants of $\tau=350 \pm 30 \mathrm{~nm}$ (control) and $\tau=150 \pm 40$ $\mathrm{nm}(\mathrm{O} 4)$. g A $\beta_{42}(15 \mu \mathrm{M})$ aggregation monitored by Thioflavin $\mathrm{T}(\mathrm{ThT})$ fluorescence in the presence of O4generated seeds $(1 \% \mathrm{v} / \mathrm{v})$. $\mathbf{h}$, Treatment of 7PA2 cells with $\mathrm{O} 4(5 \mu \mathrm{M})$ stimulates the formation of SDSresistant $A \beta$ aggregates. SDS-stable aggregates were detected by FRA (mAb 6E10). 
a

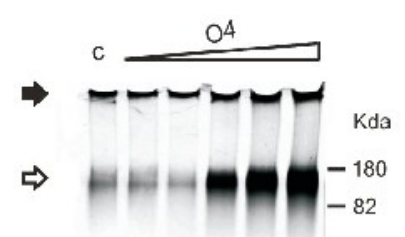

C

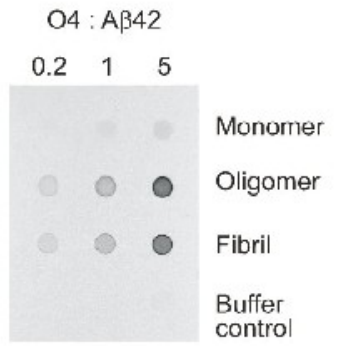

e

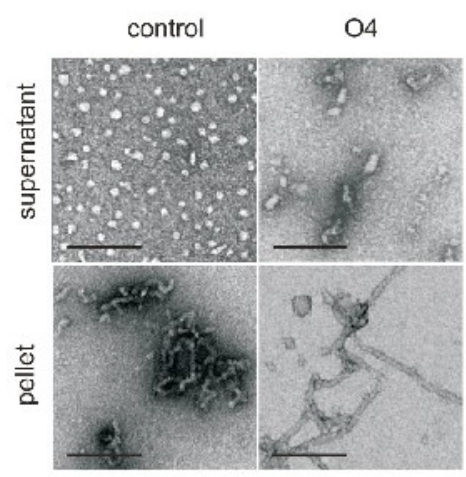

g

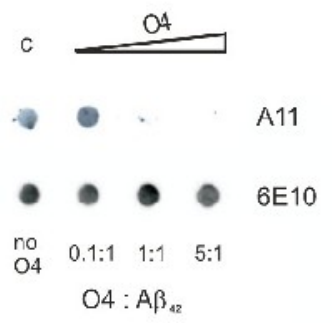

b
$4 d$

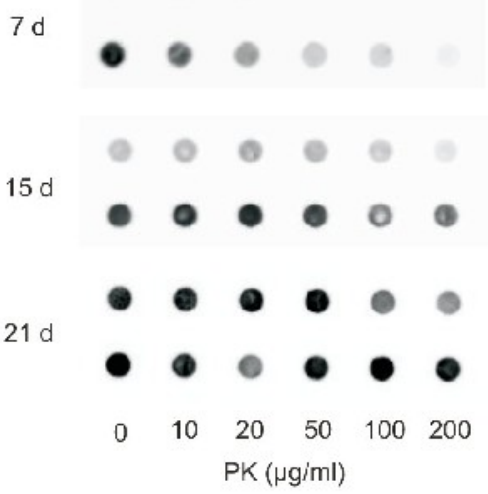

d

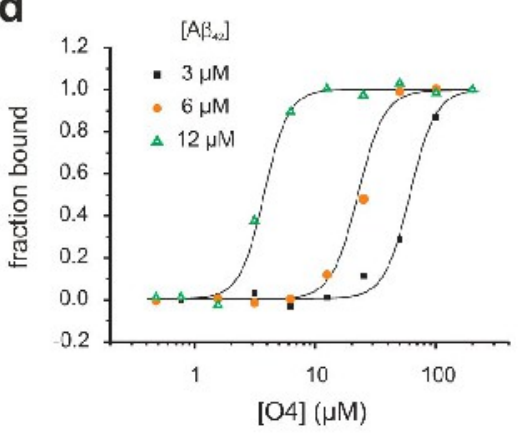

f

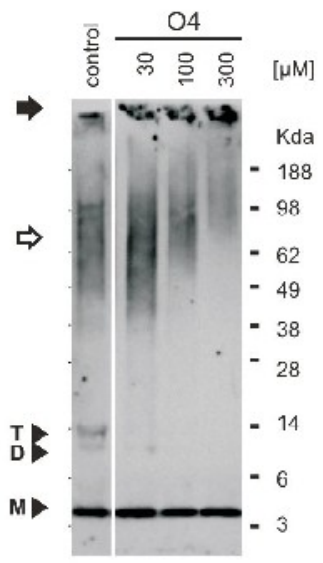

${ }_{4}$ Fig. 2: $O 4$ binds to $A \beta_{42}$ oligomers and stimulates their + conversion into SDS-stable fibrils. a, Analysis of O4generated $A \beta_{42} \quad\left(\begin{array}{lll}15 & \mu M\end{array}\right)$ aggregate species by SDS-

+ PAGE and silver staining. Aggregates were produced at $37^{\circ} \mathrm{C}$ during $48 \mathrm{~h}$. Lane 1 : control without O4; Lanes 2-6: + samples treated with 1.5, 7.5, 15,75 or $150 \mu \mathrm{M}$ O4; $\mathrm{M}$, monomer; $\mathrm{D}$, dimer; $\mathrm{T}$, trimer; open arrow, medium-size

+ oligomers; filled arrows, large SDS-insoluble aggregates. b, Analysis of SDS-stable $A \beta_{42}$ aggregates by FRA using the $6 \mathrm{E} 10$ antibody. $A \beta_{42}$ peptides $(15 \mu \mathrm{M})$ were incubated with an equimolar concentration of $\mathrm{O} 4$ and subsequently digested with proteinase $\mathrm{K}(30 \mathrm{~min}$ at $37^{\circ} \mathrm{C}$ ); c, Analysis of $\mathrm{O} 4$ binding to $A \beta_{42} \quad(15 \mu M)$ aggregate species by dot blot assays. d, Quantitative analysis of $\mathrm{O} 4$ binding to $A \beta_{42}$ oligomers. Lines represent fitting by a cooperative doseresponse curve with a Hill coefficient of 4 . e, Analysis of $A \beta_{42}(100 \mu \mathrm{M})$ oligomerization by TEM. Peptides were incubated with $\mathrm{O} 4(1 \mathrm{mM})$ for $24 \mathrm{~h}$ at $6-8^{\circ} \mathrm{C}$; soluble aggregation products (oligomers) were separated from insoluble material (protofibrils and fibrils) by centrifugation. Size bars represent $100 \mathrm{~nm}$. f, SDSPAGE and Western blot analysis of $\mathrm{O} 4$ treated $A \beta_{42}$ $\left(\begin{array}{ll}110 \mu \mathrm{M}\end{array}\right)$ oligomers after incubation with $\mathrm{O} 4$ for $24 \mathrm{~h}$; anti-A $\beta$ antibody 57-11-4. g, O4 treatment reduces the binding of anti-A $\beta$ A11 antibody to amyloid oligomers. $A \beta_{42}$ peptides $(15 \mu \mathrm{M})$ were incubated for $48 \mathrm{~h}$ with $\mathrm{O} 4$ and then analyzed by dot blot assays using the 6E10 antibody. 
a

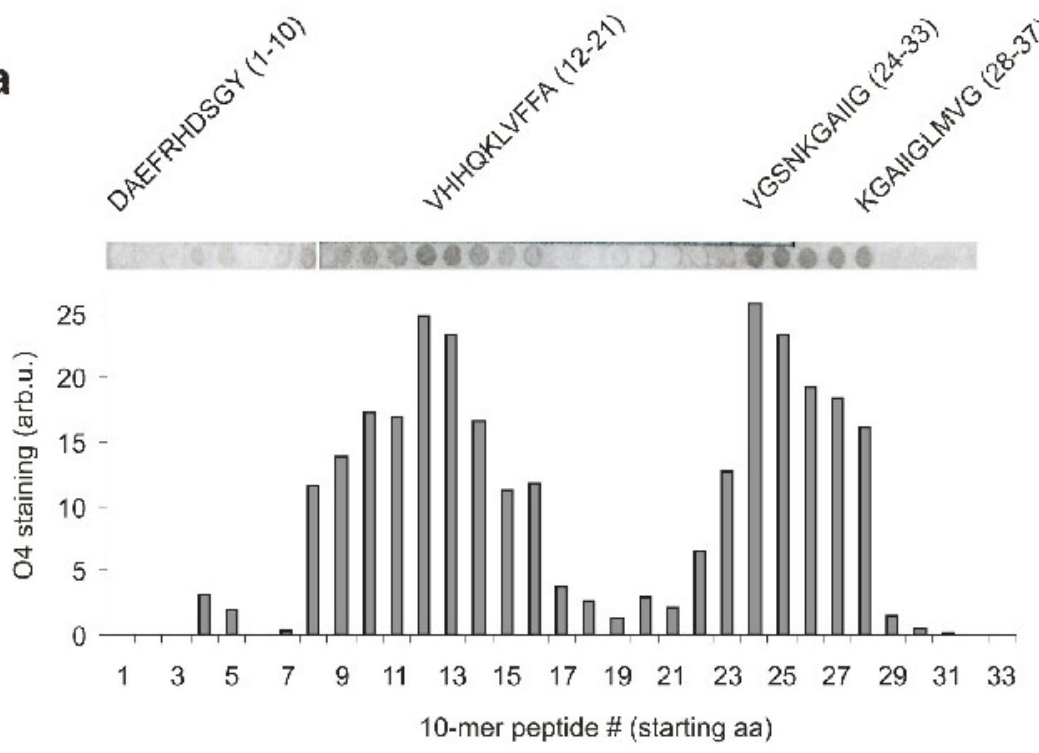

b

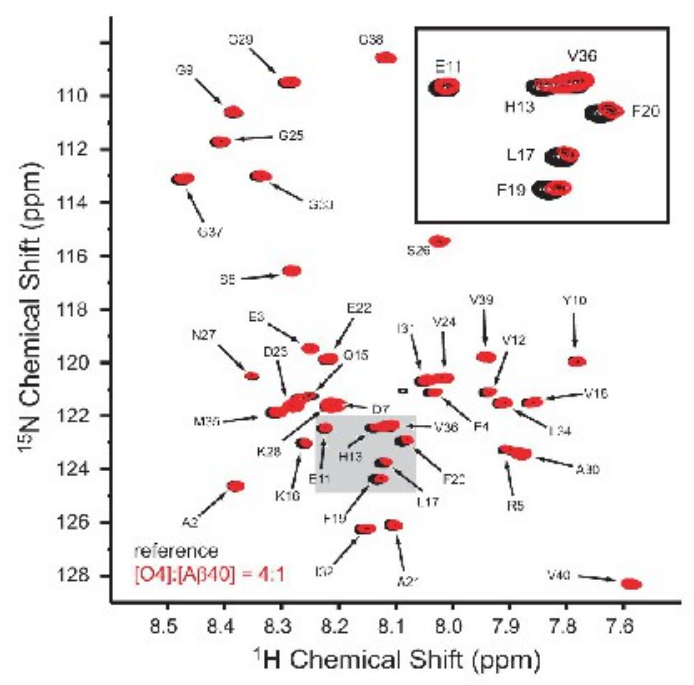

C

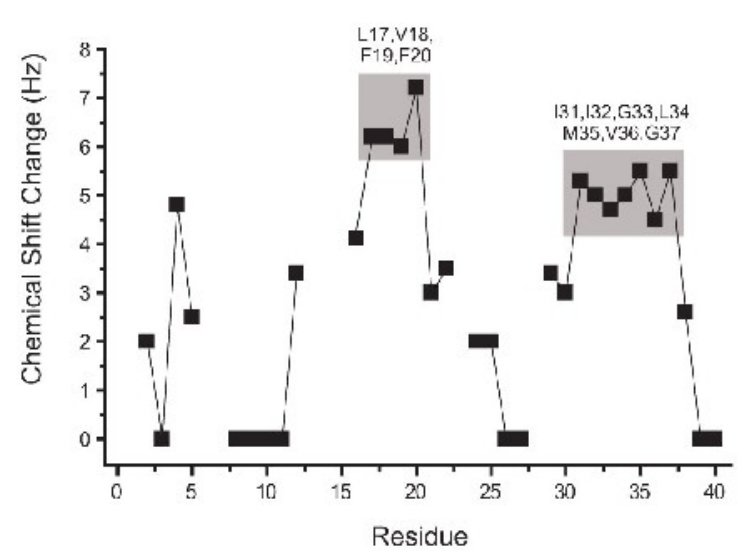

Fig. 3: $O 4$ binds to hydrophobic regions in A $\beta$ peptides. a, Incubation of a 10-mer peptide array with 04 (300 $\mu \mathrm{M})$. Peptide numbers represent the starting amino acid of 10 -mer peptides. $\mathrm{O} 4$ binding to peptides was quantified colorimetrically. Two potential $\mathrm{O} 4$ binding regions in $\mathrm{A} \beta$ peptides were detected (peptides 8-16 and 23-28). b, Interactions between $A \beta_{40}$ peptide and $\mathrm{O} 4$ monitored by solution-state NMR spectroscopy. $2 \mathrm{D}$ ${ }^{1} \mathrm{H},{ }^{15} \mathrm{~N}$ correlation spectrum obtained for $A \beta_{40}$ in presence and absence of $O 4$. The inset shows a magnification of the spectrum with resonances of the hydrophobic core region of $A \beta_{40}$ (residues 17-20). c, Chemical shift changes of $A \beta$ upon addition of 04 , employing the relation $D d_{t o t}=\sqrt{\left[D d\left({ }^{1} H\right)\right]^{2}+5\left[D d\left({ }^{15} N\right)\right]^{2}}$. 
a
6E10 (Aß 4-9)
4G8 (A $\beta$ 18-22)

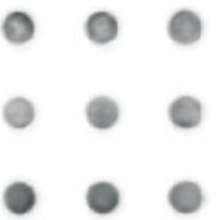
dot blot
solvent
$5 \times 04$
$10 \times 04$

C

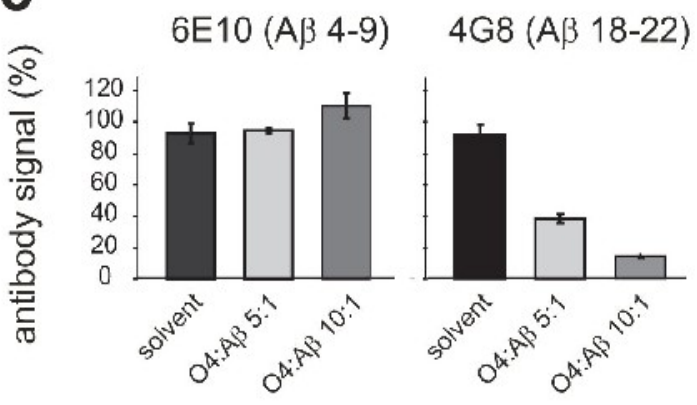

b

B10 (A $\beta$ fibril) dot blot

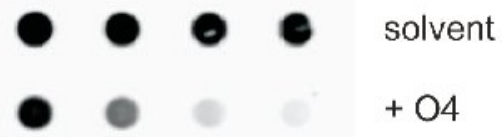

$1: 3 \quad 1: 1 \quad 5: 1 \quad 10: 1$

$\mathrm{O} 4$ : $\mathrm{A} \beta 42$

d

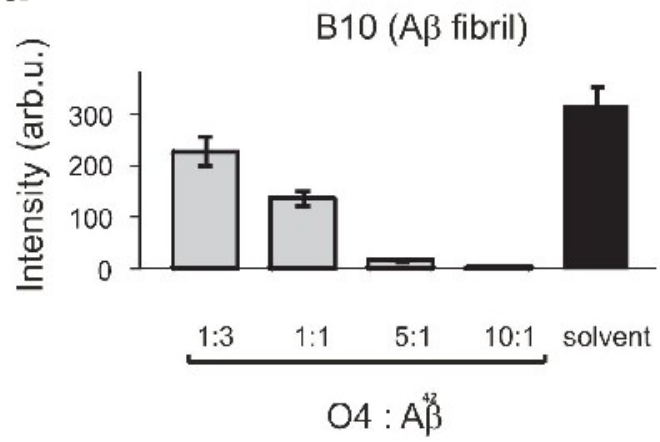

Fig. 4: $O 4$ changes the binding of anti-A $\beta$ antibodies to amyloid fibrils. a, Dot blot assays of $O 4$ treated and untreated $A \beta_{42}(15 \mu \mathrm{M})$ aggregation reactions $\left(5 \mathrm{~d}\right.$ at $\left.37^{\circ} \mathrm{C}\right)$. Aggregates were detected using the epitopespecific monoclonal anti-A $\beta$ antibodies 6E10 (aa 4-9) and $4 G 8$ (aa 18-22), respectively. O4-treatment reduces the binding of $4 \mathrm{G} 8$ but not of $6 \mathrm{E} 10$ to amyloid fibrils. $\mathbf{b}$, Bar graph quantification of triplicate samples $\pm \mathrm{SD}$ from a. c, Dot-blot assays of O4-generated $A \beta_{42}$ aggregates using the fibril-specific antibody $B 10$. $A \beta_{42}$ peptides $(15 \mu \mathrm{M})$ were incubated for $48 \mathrm{~h}$ at $37^{\circ} \mathrm{C}$ with different concentrations of $\mathrm{O} 4 . \mathrm{O} 4$ treatment reduces B10 binding to amyloid fibrils in a concentration-dependent manner. d, Bar graph quantification of triplicate samples \pm SD from $\mathrm{C}$. 
a

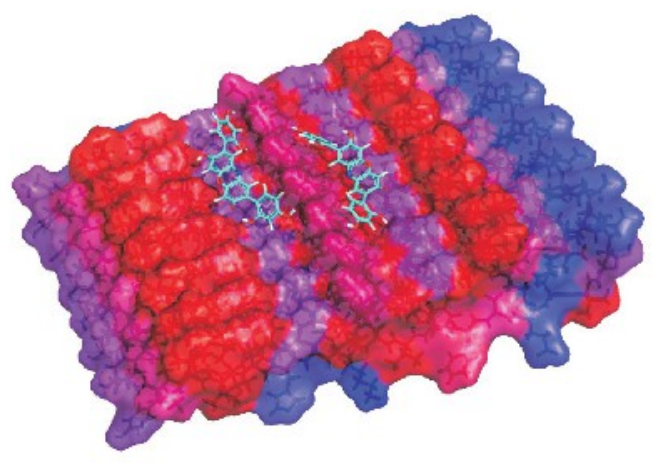

b

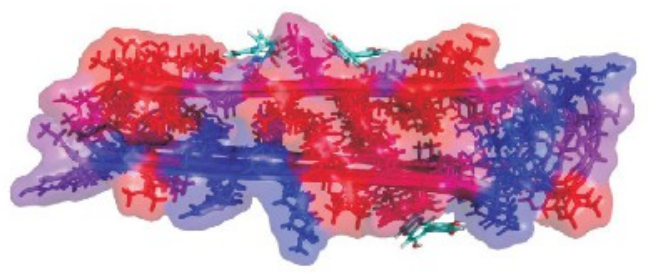

C

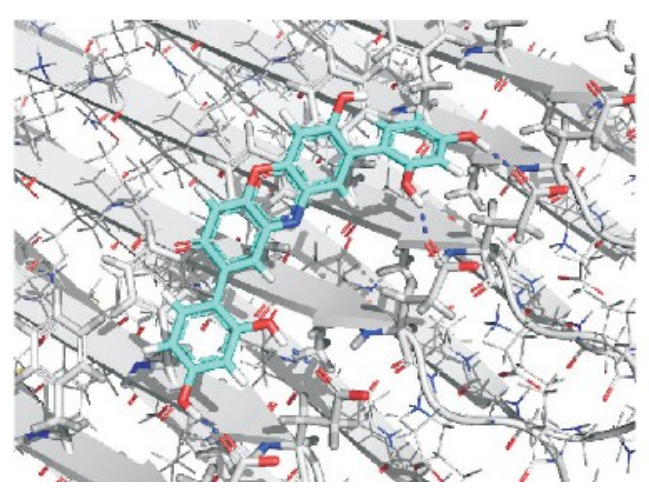

Fig. 5: $\mathrm{O} 4$ binds to hydrophobic grooves on the surface of $\beta$-sheet-rich $A \beta_{42}$ fibrils. $a$, Computational docking studies predict that $\mathrm{O} 4$ binds parallel to the long fibril axis targeting hydrophobic grooves at aa 33-35 or 3537. Binding to aa 33-35 and 35-37 was predicted to be mutually exclusive. b. Side view of an $A \beta_{42}$ fibril with $\mathrm{O} 4$ molecules bound to aa 20-21, 33-35 and 35-37. c, Predicted interaction of the oxazine ring in $\mathrm{O} 4$ with phenylalanine 20 (F20) in $A \beta_{42}$ fibrils. 
a

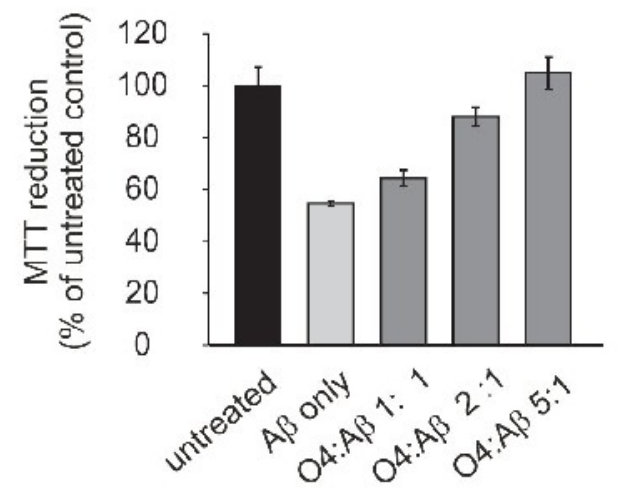

C

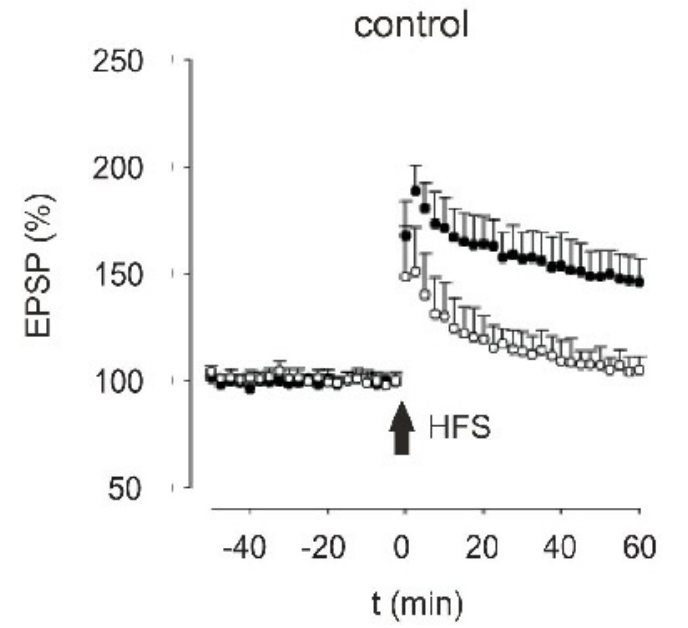

b
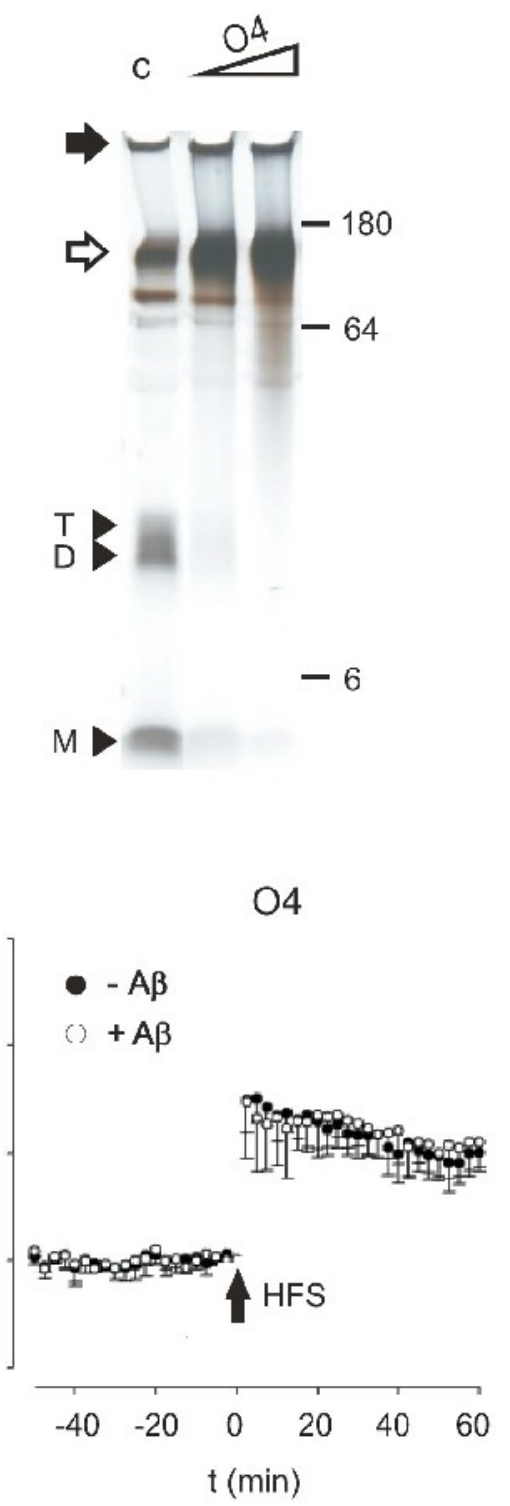

Fig. 6: O4-mediated acceleration of $A \beta_{42}$ fibrillogenesis correlates with reduced cellular toxicity and improves synaptic transmission in brain slices. a, O4 treatment reduces $A \beta_{42}$ toxicity in a SHSY5Y cell model. $A \beta_{42}$ peptides $(5 \mu \mathrm{M})$ and $\mathrm{O} 4$ were added to the culture medium of differentiated SHSY5Y cells and toxicity was monitored after an incubation period of $48 \mathrm{~h}$ using an MTT assay. $\mathrm{O} 4$ treatment improved cell viability in a concentration-dependent manner. b. Addition of O4 $(5 \mu \mathrm{M}$ or $25 \mu \mathrm{M})$ to SHSY5Y cell cultures promotes A $\beta_{42}$ $(5 \mu \mathrm{M})$ aggregation, reducing the levels of soluble monomers and small oligomers. Samples were incubated for $48 \mathrm{~h}$ and analyzed by SDS-PAGE and silver staining. c, O4 treatment reduces $A \beta_{42}$-induced inhibition of long-term potentiation (LTP) in hippocampal rat brain slices. LTP of excitatory post-synaptic potentials (EPSP) was evoked by high-frequency stimulation (HFS). 


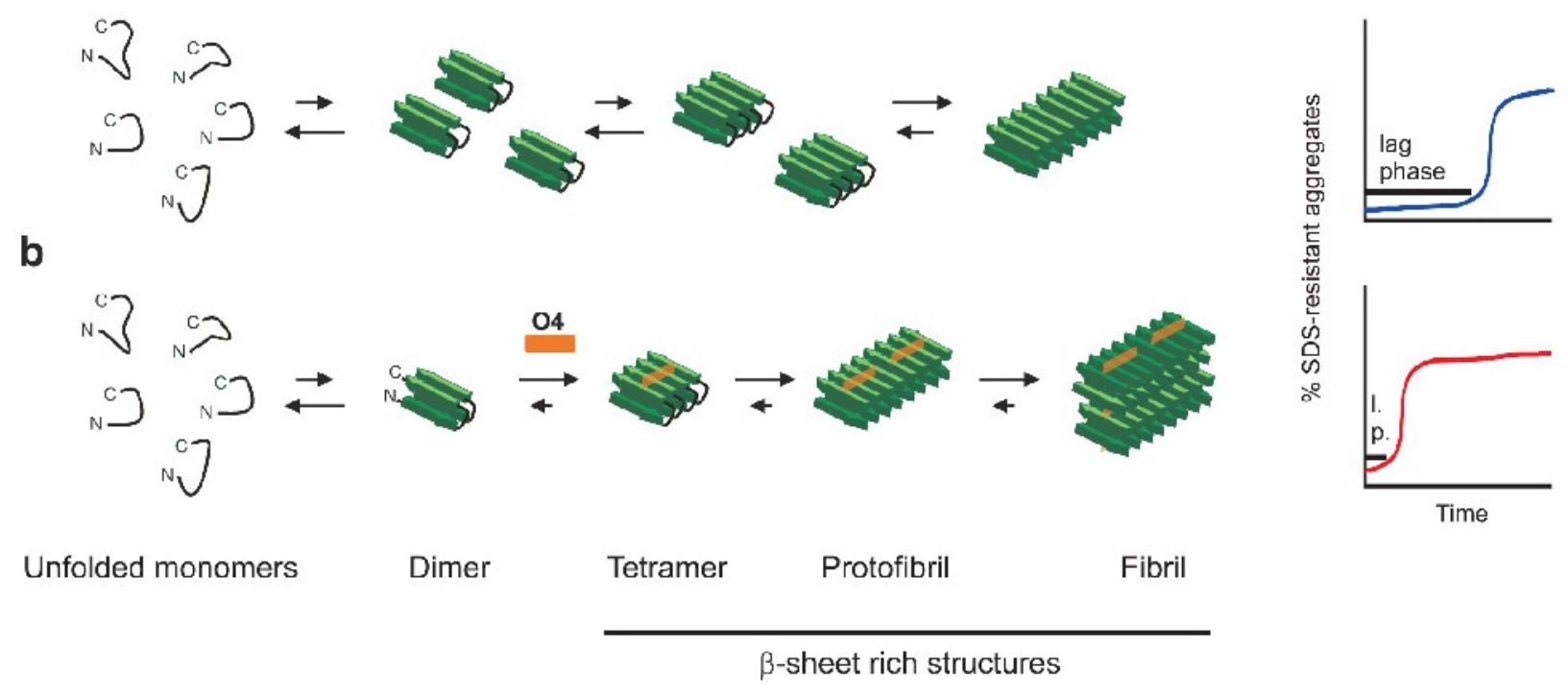

Fig. 7: Working model of effects of $O 4$ on spontaneous $A \beta_{42}$ polymerization. a, Untreated, spontaneous $A \beta_{42}$ aggregation reaction. Seeding-competent, $\beta$-sheet-rich $A \beta_{42}$ aggregates (oligomers and protofibrils) are slowly formed during the nucleation (lag) phase by association of monomers. b, In $\mathrm{O} 4$ treated reactions formation of amyloid fibrils is accelerated because compound binding to $\beta$-sheet-rich small aggregates stabilizes the formation of low molecular weight prefibrillar structures (tetramers, protofibrils etc.) that polymerize efficiently into mature amyloid fibrils. Thus, $\mathrm{O} 4$ treatment of heterogeneous $A \beta_{42}$ aggregation reactions alters the kinetics of amyloid polymerization, leading to a reduced lag phase followed by a rapid exponential fibril growth phase (c). 


\section{References}

1. Soto, C. et al. Beta-sheet breaker peptides inhibit fibrillogenesis in a rat brain model of amyloidosis: implications for Alzheimer's therapy. Nat Med 4, 822-6 (1998).

2. Walsh, D.M. \& Selkoe, D.J. A beta oligomers - a decade of discovery. J Neurochem 101, 1172-84 (2007).

3. Harper, J.D. \& Lansbury, P.T., Jr. Models of amyloid seeding in Alzheimer's disease and scrapie: mechanistic truths and physiological consequences of the time-dependent solubility of amyloid proteins. Annu Rev Biochem 66, 385-407 (1997).

4. Stefani, M. \& Dobson, C.M. Protein aggregation and aggregate toxicity: new insights into protein folding, misfolding diseases and biological evolution. J Mol Med 81, 678-99 (2003).

5. Chimon, S. et al. Evidence of fibril-like beta-sheet structures in a neurotoxic amyloid intermediate of Alzheimer's beta-amyloid. Nat Struct Mol Biol (2007).

6. Mastrangelo, I.A. et al. High-resolution atomic force microscopy of soluble Abeta42 oligomers. J Mol Biol 358, 106-19 (2006).

7. Ahmed, M. et al. Structural conversion of neurotoxic amyloid-beta(1-42) oligomers to fibrils. Nat Struct Mol Biol 17, 561-7 (2010).

8. Bucciantini, M. et al. Inherent toxicity of aggregates implies a common mechanism for protein misfolding diseases. Nature 416, 507-11 (2002).

9. Herbst, M. \& Wanker, E.E. Therapeutic approaches to polyglutamine diseases: combating protein misfolding and aggregation. Curr Pharm Des 12, 2543-55 (2006).

10. Yang, D.S., Yip, C.M., Huang, T.H., Chakrabartty, A. \& Fraser, P.E. Manipulating the amyloid-beta aggregation pathway with chemical chaperones. J Biol Chem 274, 32970-4 (1999).

11. Ghanta, J., Shen, C.L., Kiessling, L.L. \& Murphy, R.M. A strategy for designing inhibitors of beta-amyloid toxicity. J Biol Chem 271, 29525-8 (1996).

12. McLaurin, J. et al. Cyclohexanehexol inhibitors of Abeta aggregation prevent and reverse Alzheimer phenotype in a mouse model. Nat Med 12, 801-8 (2006).

13. Williams, A.D. et al. Structural properties of Abeta protofibrils stabilized by a small molecule. Proc Natl Acad Sci U S A 102, 7115-20 (2005).

14. Conway, K.A., Rochet, J.C., Bieganski, R.M. \& Lansbury, P.T., Jr. Kinetic stabilization of the alpha-synuclein protofibril by a dopamine-alpha-synuclein adduct. Science 294, 1346-9 (2001).

15. Walsh, D.M. et al. Naturally secreted oligomers of amyloid beta protein potently inhibit hippocampal longterm potentiation in vivo. Nature 416, 535-9 (2002).

16. Necula, M., Kayed, R., Milton, S. \& Glabe, C.G. Small molecule inhibitors of aggregation indicate that amyloid beta oligomerization and fibrillization pathways are independent and distinct. J Biol Chem 282, 10311-24 (2007).

17. Ehrnhoefer, D.E. et al. Green tea (-)-epigallocatechin-gallate modulates early events in huntingtin misfolding and reduces toxicity in Huntington's disease models. Hum Mol Genet 15, 2743-51 (2006).

18. Ehrnhoefer, D.E. et al. EGCG redirects amyloidogenic polypeptides into unstructured, off-pathway oligomers. Nat Struct Mol Biol 15, 558-66 (2008).

19. Bieschke, J. et al. EGCG remodels mature alpha-synuclein and amyloid-beta fibrils and reduces cellular toxicity. Proc Natl Acad Sci U S A 107, 7710-5 (2010).

20. LeVine, H. The challenge of inhibiting Abeta polymerization. Curr Med Chem 9, 1121-33 (2002).

21. Kim, W. \& Hecht, M.H. Generic hydrophobic residues are sufficient to promote aggregation of the Alzheimer's Abeta42 peptide. Proc Natl Acad Sci U S A 103, 15824-9 (2006).

22. Heiser, V. et al. Identification of benzothiazoles as potential polyglutamine aggregation inhibitors of Huntington's disease by using an automated filter retardation assay. Proc Natl Acad Sci U S A 99 Suppl 4, 16400-6 (2002).

23. Beecken, H. et al. Orcein and litmus. Biotech Histochem 78, 289-302 (2003).

24. Walsh, D.M. et al. Amyloid beta-protein fibrillogenesis. Structure and biological activity of protofibrillar intermediates. J Biol Chem 274, 25945-52 (1999).

25. Luhrs, T. et al. 3D structure of Alzheimer's amyloid-beta(1-42) fibrils. Proc Natl Acad Sci U S A 102, 17342-7 (2005).

26. LeVine, H., 3rd. Quantification of beta-sheet amyloid fibril structures with thioflavin T. Methods Enzymol 309, 274-84 (1999).

27. Yang, W., Dunlap, J.R., Andrews, R.B. \& Wetzel, R. Aggregated polyglutamine peptides delivered to nuclei are toxic to mammalian cells. Hum Mol Genet 11, 2905-17 (2002).

28. Ma, Q.L. et al. Antibodies against beta-amyloid reduce Abeta oligomers, glycogen synthase kinase-3beta activation and tau phosphorylation in vivo and in vitro. $J$ Neurosci Res 83, 374-84 (2006). 
29. Paz, M.A., Fluckiger, R., Boak, A., Kagan, H.M. \& Gallop, P.M. Specific detection of quinoproteins by redoxcycling staining. J Biol Chem 266, 689-92 (1991).

30. Lambert, M.P. et al. Diffusible, nonfibrillar ligands derived from Abeta1-42 are potent central nervous system neurotoxins. Proc Natl Acad Sci U S A 95, 6448-53 (1998).

31. Kayed, R. et al. Common structure of soluble amyloid oligomers implies common mechanism of pathogenesis. Science 300, 486-9 (2003).

32. Beutling, U., Stading, K., Stradal, T. \& Frank, R. Large-scale analysis of protein-protein interactions using cellulose-bound peptide arrays. Adv Biochem Eng Biotechnol 110, 115-52 (2008).

33. Caputo, C.B., Fraser, P.E., Sobel, I.E. \& Kirschner, D.A. Amyloid-like properties of a synthetic peptide corresponding to the carboxy terminus of beta-amyloid protein precursor. Arch Biochem Biophys 292, 199-205 (1992).

34. Feng, B.Y. et al. Small-molecule aggregates inhibit amyloid polymerization. Nat Chem Biol 4, 197-9 (2008).

35. Kim, K.S. Production and characterization of monoclonal antibodies reactive to synthetic cerebrovascular amyloid peptide. Neuroscience Research Communications 2, 121-130 (1988).

36. Habicht, G. et al. Directed selection of a conformational antibody domain that prevents mature amyloid fibril formation by stabilizing Abeta protofibrils. Proc Natl Acad Sci U S A 104, 19232-7 (2007).

37. Friesner, R.A. et al. Extra precision glide: docking and scoring incorporating a model of hydrophobic enclosure for protein-ligand complexes. J Med Chem 49, 6177-96 (2006).

38. Hansen, M.B., Nielsen, S.E. \& Berg, K. Re-examination and further development of a precise and rapid dye method for measuring cell growth/cell kill. J Immunol Methods 119, 203-10 (1989).

39. Wang, Q., Walsh, D.M., Rowan, M.J., Selkoe, D.J. \& Anwyl, R. Block of long-term potentiation by naturally secreted and synthetic amyloid beta-peptide in hippocampal slices is mediated via activation of the kinases c-Jun Nterminal kinase, cyclin-dependent kinase 5, and p38 mitogen-activated protein kinase as well as metabotropic glutamate receptor type 5. J Neurosci 24, 3370-8 (2004).

40. Hamaguchi, T., Ono, K. \& Yamada, M. Anti-amyloidogenic therapies: strategies for prevention and treatment of Alzheimer's disease. Cell Mol Life Sci 63, 1538-52 (2006).

41. Pallitto, M.M., Ghanta, J., Heinzelman, P., Kiessling, L.L. \& Murphy, R.M. Recognition sequence design for peptidyl modulators of beta-amyloid aggregation and toxicity. Biochemistry 38, 3570-8 (1999).

42. Reixach, N., Crooks, E., Ostresh, J.M., Houghten, R.A. \& Blondelle, S.E. Inhibition of beta-amyloid-induced neurotoxicity by imidazopyridoindoles derived from a synthetic combinatorial library. J Struct Biol 130, 247-58 (2000).

43. Howlett, D.R. et al. Inhibition of fibril formation in beta-amyloid peptide by a novel series of benzofurans. Biochem J 340 ( Pt 1), 283-9 (1999).

44. Tomiyama, T. et al. Rifampicin prevents the aggregation and neurotoxicity of amyloid beta protein in vitro. Biochem Biophys Res Commun 204, 76-83 (1994).

45. Lauren, J., Gimbel, D.A., Nygaard, H.B., Gilbert, J.W. \& Strittmatter, S.M. Cellular prion protein mediates impairment of synaptic plasticity by amyloid-beta oligomers. Nature 457, 1128-32 (2009).

46. Harmeier, A. et al. Role of amyloid-beta glycine 33 in oligomerization, toxicity, and neuronal plasticity. $J$ Neurosci 29, 7582-90 (2009).

47. McLaurin, J., Golomb, R., Jurewicz, A., Antel, J.P. \& Fraser, P.E. Inositol stereoisomers stabilize an oligomeric aggregate of Alzheimer amyloid beta peptide and inhibit abeta -induced toxicity. J Biol Chem 275, 18495 502 (2000).

48. Ladiwala, A.R. et al. Resveratrol selectively remodels soluble oligomers and fibrils of amyloid Abeta into offpathway conformers. J Biol Chem 285, 24228-37.

49. Cheng, I.H. et al. Accelerating amyloid-beta fibrillization reduces oligomer levels and functional deficits in Alzheimer disease mouse models. J Biol Chem 282, 23818-28 (2007). 